\title{
PROCESSO DE ESCOLHA NA AQUISIÇÃO DO DESIGN DE SUPERFÍCIE: PARA AMBIENTES NA REGIÃO DE BALNEÁRIO CAMBORIÚ
}

\author{
Alais Souza Ferreira \\ Estudante de Especialização em Marketing Criativo - UNIVALI \\ alais.ferreira@live.com \\ Eliete Auxiliadora Assunção Ourives \\ Doutora em Engenharia de Produção - UFSC \\ elieteourives@gmail.com \\ Gustavo D’Amaral P. Granja Russo \\ Mestre em Design - UDESC \\ gustavogranjarusso@hotmail.com
}

Resumo: A ilustração é uma ótima forma de comunicação em textos e outros suportes, que necessitam transmitir um conceito e uma mensagem. Ela está integrada na área de design de superfície, que se relaciona com amplas áreas do design. O ilustrador busca explorar as superfícies para agregar valor simbólico e emocional aos produtos, atingindo a exclusividade que é um importante aspecto comercial, pois o mercado está se direcionando para a customização e o aumento de opções de escolha. Portanto, buscou-se focar em design de interiores voltado para revestimentos, já que as padronagens encontram-se muito presentes nos ambientes contemporâneos, agregando ao mesmo conceito, cor e forma, e tornando viável a personalização do espaço. Além disso, a padronagem e o design de superfície contribuem para a identidade e originalidade das empresas. Com isso, surgiu o problema: por que as pessoas compram design de superfície para ambientes? Para atingir o principal objetivo foi preciso conhecer as aplicações do design de superfície, selecionar quais delas são comercializáveis, e verificar o problema por meio de pesquisa qualitativa com 12 arquitetos e 12 designers, na região de Balneário Camboriú. A metodologia utilizada foi a de Rodrigues (2007), que foi adaptada e possui três etapas. Na análise dos dados foi identificada a hipótese de que as pessoas, da região de Balneário Camboriú, compram design de superfície para ambientes a fim de personalizá-los.

Palavras-chave: Ilustração, design de superfície, ambientes.

Abstract: The illustration is an efficiently form of communication, in texts and in other media that require transmitting a concept and a message. The same is integrated in the area of Surface Design, which is related with embracing Design areas. The Illustrator tries to explore surfaces for symbolic and emotional value to products, reaching the exclusivity which is 
an important commercial aspect, because the market is directed to the customization and increased options to choose from. Therefore, we sought to focus on interior design geared for coatings, since the patterns are present in contemporary environments, adding to the same concept, color and shape, and making feasible the personalization of space. In addition, the pattern and the surface design contribute to the identity and originality. And there it has born the problem: why do people buy surface design for environments? To achieve the main objective, it was necessary to meet the applications of surface design, selected which ones are marketable and verifies the problem by means of qualitative research with 12 architects and 12 designers, from Balneário Camboriú. The methodology used was that of Rodrigues (2007), which was adapted and has three steps. In the analysis of the data was identified the chance that people, in the region of Balneario Camboriú, buy surface design for environments in order to customize them.

Palavras-chave: illustration, surface design, environments.

\section{INTRODUÇÃO}

Conforme a Associação Brasileira dos llustradores Profissionais - ABIPRO (2006) a ilustração é considerada como todo ofício utilizado para representar textos, temas, ideias e conceitos, dando a estes forma e conteúdo concreto, além de transmitir clima, sentimentos, sensações e acrescentar à ideia inicial a ambientação necessária para transmiti-la de maneira amplificada. Dessa forma, ela é considerada uma boa forma de comunicação não apenas em textos, como também em outros suportes que necessitam transmitir um conceito e uma mensagem.

A ilustração é composta por um conjunto de elementos significativos que se tornam uma inspiração para o ilustrador. E "tendo-a, então, como linguagem visual compatível com o período na qual se encontra, pode-se [...] entendê-la como integrante da área denominada design de superfície" (RABELO E MATOS, 2011, p.8).

Com isso, o ilustrador busca explorar as superfícies para agregar valor simbólico e emocional aos produtos, atingindo a exclusividade, uma vez que "[...] a conjuntura de mercado atual tende para a customização e o crescente aumento de opções de escolha" (RÜTHSCHILLING, 2008, p.57). Isso também se reflete no design de superfície, que segundo Freitas (2012), busca atribuir um significado comunicativo ao objeto, transmitindo informações sígnicas percebidas pelos sentidos (como cores, texturas e grafismos), fornecendo personalização as superfícies dos ambientes ou objetos.

Segundo Rubim (2004), o design de superfície é um termo muito utilizado, nos Estados Unidos, para definir todo projeto elaborado por um designer, no que diz respeito ao tratamento e cor utilizados em uma superfície industrial ou não. E não se relaciona apenas com o design industrial ou têxtil, vai além a outras áreas do Design.

O Design de Superfície abrange o Design Têxtil (em todas as especialidades), o de papéis (idem), o cerâmico, o de plásticos, de emborrachados, desenhos e/ou cores sobre utilitários (por exemplo, louça). Também pode ser um precioso complemento ao Design Gráfico quando participa de uma ilustração, ou como fundo de uma peça gráfica, ou em Web-Design. Rubim (RUBIM, 2004, p.2) 
Conforme o site Mdesign Brasil (2010), o design de superfície aborda a criação de imagens bidimensionais projetadas para a geração de padrões e texturas, que se desenvolvem de forma contínua sobre várias superfícies, levando em consideração os princípios básicos do design em busca das melhores soluções projetuais.

Portanto, é necessário saber explorá-lo e identificar as oportunidades existentes nele. Dessa forma, o artigo busca focar em design de superfície para ambientes de interiores, entrando na área de revestimentos. Nesse sentido, Gubert (2011) afirma que as padronagens estão cada vez mais presentes no design de interiores contemporâneo, agregando cor e forma aos ambientes com elementos de linguagem de fácil interpretação para os usuários. Isso é um importante recurso técnico para o design de interiores, pois torna possível a personalização do espaço. "[...] O mercado utiliza as padronagens como um diferencial, agregando valores conceituais aos produtos" e ambientes (GUBERT, 2011, p.121).

Além disso, a padronagem e o design de superfície podem contribuir diretamente para a identidade e originalidade de uma empresa, sendo importante para a sua comunicação. "Como elemento compositivo no design de interiores, seja ocupando uma grande área, seja um detalhe, a padronagem contribui significativamente na construção da identidade do ambiente" (GUBERT, 2011, p.121).

Os autores indicam que a razão pela qual as pessoas compram design de superfície é a personalização, mas outros informam que é pela funcionalidade, outros ainda afirmam que é para esconder imperfeições, mas não existe nenhuma pesquisa científica que comprove essas informações. Nesse contexto, surge o problema de pesquisa "o motivo pelo qual as pessoas compram design de superfície para ambientes", buscando tornar científica a hipótese dos autores. Para atingir esse objetivo é preciso conhecer as possíveis aplicações do design de superfície, selecionar e identificar quais aplicações são comercializáveis, e verificar o problema por meio de pesquisa qualitativa com 12 arquitetos e 12 designers, totalizando 22 profissionais.

A Metodologia escolhida é de Rodrigues (2007), que foi adaptada, possuindo três etapas: Formulação do Problema e Hipótese (1a Etapa), Pesquisa (2 2 a Etapa) e Pesquisa de Campo (3a Etapa). Segundo Rodrigues (2007, p.1) “Metodologia Científica é um conjunto de abordagens, técnicas e processos utilizados pela ciência para formular e resolver problemas de aquisição objetiva do conhecimento, de uma maneira sistemática". Foi realizada a pesquisa exploratória visando descobrir uma hipótese para o problema de pesquisa, e a revisão bibliográfica para embasar a fundamentação teórica. Para a coleta de dados, foi realizada uma pesquisa de campo qualitativa, por meio de questionário via e-mail, com 12 arquitetos e 12 designers da região de Balneário Camboriú. A amostra definida é composta por Arquitetos e Designers formados, que trabalham na área de interiores há pelo menos 2 anos, e que entendem sobre design de superfície e suas utilidades.

Para a apresentação dos dados e análise dos resultados, foi utilizado um método quantitativo do Bardin (2009, p.121) conhecido como as "Fases da Análise de Conteúdo". Neste método são extraídas palavras-chave das repostas dos questionários, a fim de codificá-las em unidades e serem enumeradas de acordo com a frequência e a intensidade com que foram citadas. Depois as palavras-chave foram agrupadas em categorias, de acordo com a codificação do conteúdo dos dados e com as hipóteses da investigação. E por fim, foi feito o registro e quantificação dos dados conforme as categorias escolhidas. A interpretação e análise dos dados foram feitas a 
partir das categorias quantificadas ou tabeladas (chamado como agrupamento de dados) com as palavras-chave retiradas dos dados.

\section{ILUSTRAÇÃO}

De acordo com Ribeiro (2010, p.15) "a llustração é uma forma de expressão artística que existe para comunicar uma mensagem pré-estabelecida. Serve um propósito, uma solicitação ou um cliente que pretende comunicar uma ideia através de uma linguagem não verbal". Já Antunes (2007, p.4) contradiz esse pensamento informando que "nas Artes Plásticas a obra não necessita de um propósito específico, é algo interpretativo, [...]. Na llustração é o contrário, existe uma mensagem clara e definida, que precisa ser comunicada e recebida conforme o ilustrador a concebeu". Com isso, a mesma necessita de um propósito específico, não sendo apenas uma expressão artística, para que transmita uma mensagem clara e definida por meio de uma linguagem não verbal, buscando atender a necessidade de um cliente.

Castagini e Balvedi (2010, p.8) informam que "a partir da metade da década de 90, a ilustração invadiu o meio digital e o uso do computador para a criação de imagens, foi se especializando e popularizando. Novos materiais e softwares foram desenvolvidos especialmente para este fim". Então os ilustradores começam a mesclar técnicas manuais com as digitais, e alguns utilizam somente a ilustração digital, como na tecnologia 3D, tornando-as muito mais realísticas. Segundo Steagall (2008) o Renascimento inaugurou a ilusão de profundidade, com a perspectiva, que possui um lugar fundamental na representação da realidade.

Dessa forma, o ilustrador vem conquistando seu espaço de prestígio no mercado, e explorando diferentes superfícies com a técnica digital e a ilusão de ótica. Segundo Rabelo e Matos (2011) ele estampa suas ideias em superfícies que variam de paredes a tecidos, isso vem sendo item fundamental no processo de decisão de compra de uma sociedade consumidora contemporânea, que está voltada para a personalização e customização dos objetos.

Freitas (2009, apud RABELO e MATOS, 2011, p.7-8) defende que a ilustração acompanha essa sociedade pós-moderna de sucessivas transformações onde "a rapidez de informações, a efemeridade de comportamentos sociais necessitam de uma expressão artística que envolva os elementos atuais de subjetividade comportamental". E é exatamente por isso que o ilustrador atua como uma ponte entre as expectativas do cliente (inspirações e interpretações do ilustrador) e dos consumidores finais (sendo necessário direcionar, adequar e adaptar esse fluxo criativo para públicos específicos) (RABELO e MATOS, 2011).

Portanto, as ilustrações e a experiências visuais buscam reconhecer uma dimensão que vai além do que os olhos enxergam, ou seja, uma ilustração bidimensional com ilusão de ótica. Além disso, a mesma passou a acolher e explorar muitas áreas como o design de superfície. Noble (2003) informa que ela é uma disciplina ligada ao design que atravessou um período de redefinição significativa, onde sua atividade prática e criação passaram a acolher várias abordagens. Dessa forma, o foco passa a ser o design de superfície voltado para ambientes. 


\title{
3. DESIGN DE SUPERFÍCIE
}

O design de superfície surgiu nos Estados Unidos, é a tradução de Surface Design, e foi introduzido por Renata Rubim no Brasil em 1980 (RUBIM, 2004). Esse nome é utilizado por ser mais abrangente que as denominações usadas no Brasil como design têxtil e desenho (industrial) de estamparia, que se referem apenas ao campo têxtil e impressão de desenhos sobre tecidos (RÜTHSCHILLING, 2002). Segundo Zorgi (2008), design de superfície é todo projeto de tratamento dado a uma superfície seja ela contínua ou não. De acordo com Schwartz (2008) o

\begin{abstract}
Design de Superfície é uma atividade projetual que atribui características perceptivas expressivas à Superfície dos objetos, concretas ou virtuais, pela configuração de sua aparência, principalmente por meio de texturas visuais, táteis e relevos, com o objetivo de reforçar ou minimizar as interações sensório-cognitivas entre o objeto e o sujeito. Tais características devem estar relacionadas às estéticas, simbólicas e práticas (funcionais e estruturais) dos artefatos das quais fazem parte, podendo ser resultantes tanto da configuração de objetos pré-existentes em sua camada superficial quanto do desenvolvimento de novos objetos a partir da estruturação de sua superfície. (SCHWARTZ, 2008, p.146)
\end{abstract}

Dessa forma, o design de superfície não é apenas uma padronagem, textura ou ilustração, é uma atividade projetual que busca adicionar um significado comunicativo à superfície - suas características devem estar aliadas à estética, simbologia, funcionalidade e estrutura - a ser trabalhada.

Segundo Rubim (2004, p.21), design de superfície é "todo projeto elaborado por um designer, no que diz respeito ao tratamento e cor utilizados numa superfície, industrial, ou não", oriundo de um processo criativo, original e único. Por isso, o mesmo se diferencia da arte por ser um projeto executado pelo profissional formado em design, além de que visa atribuir um caráter funcional à superfície "como, por exemplo, desenvolver a estamparia de uma toalha de mesa, um papel de parede, uma superfície cerâmica" (ZORGI, 2008, p.19). E para Rüthschilling (2006) o mesmo

é uma atividade técnica e criativa cujo objetivo é a criação de imagens bidimensionais (texturas visuais e tácteis), projetadas especificamente para a constituição e/ou tratamento de superfícies, apresentando soluções estéticas e funcionais adequadas aos diferentes materiais e processos de fabricação artesanal e industrial.

Além disso, o design de superfície pode ser definido em bidimensional quando trabalhado em uma superfície que possui altura e largura, e tridimensional quando trabalhado em um objeto com altura, largura e profundidade. Paschoarelli \& Silva (2002, apud RINALDI, 2009) afirmam que os aspectos bidimensionais caracterizam-se pelo design gráfico, pois a área se baseia nas atividades de representação e linguagem visual trabalhadas em duas dimensões: altura e largura. Por sua vez, os aspectos tridimensionais caracterizam-se pelo design de produto, onde são analisados e desenvolvidos objetos com três dimensões (altura, largura e profundidade).

O design de superfície compreende inúmeras áreas, que segundo Rubim (2004, p.22) "abrange o design têxtil [...], o de papéis [...], o cerâmico, o de plásticos, de emborrachados, desenho e/ou cores sobre utilitários (por exemplo, louça)", além de que pode ser um complemento ao design gráfico. Por este motivo, ele possui vários 
tipos de aplicações como adesivos, estampas para tecidos, papeis de parede, vasos, além de "outras superfícies que podem receber aplicação através de projetos interessantes, tais como vidro e emborrachados", pois esses materiais ainda não foram suficientemente explorados (ZORGI, 2008, p.19).

Sendo assim, é possível estabelecer três abordagens para o mesmo: a representacional que se apoia na geometria e representação gráfica; a constitucional que envolve os materiais e processos técnicos utilizados na confecção do produto; e a relacional que enfatiza as afinidades entre sujeito, objeto e o meio (semântica, cultural, ergonômica, produtiva, mercadológica) (SCHWARTZ, 2008). Essas abordagens podem interferir com maior ou menor intensidade na configuração da superfície do objeto, por isso, é importante identificar o tipo de abordagem antes de começar a trabalhar com uma superfície.

Dessa forma, o designer precisa estar atento e se especializar na área para ter "conhecimento sobre as técnicas e processos (industriais) que poderão ser usados na fabricação do produto [...] projetado (estamparia, serigrafia, matrizaria, tecelagem) e materiais para controlar os efeitos visuais desejados" (ZORGI, 2008, p.20).

Existem dois tipos de projetos representacionais sobre uma superfície, o primeiro com repetição onde o módulo é colocado lado a lado gerando um padrão gráfico contínuo, e o segundo com um grafismo como se houvesse apenas um módulo sem existir continuidade (RUBIM, 2004; RINALDI, 2009).

A repetição é muito importante para o efeito visual, pois não é apenas fazer uma forma e reproduzi-la igual para ambos os lados. Conforme Zorgi (2008) a mesma é a organização dos elementos formais contidos no desenho em unidades ou módulos, que se repetem nos intervalos constantes, de acordo com um sistema determinado, gerando um padrão. Compreender como ela é desenvolvida é um pré-requisito importante ao designer de superfície, tanto do ponto de vista técnico como da possibilidade de expressão, pois na repetição do módulo podem surgir diferenças visuais inesperadas, porém interessantes, provocando um diálogo com o seu criador.

Para Rüthschilling (2002) os padrões gerados com o projeto de superfícies se desenvolvem de modo contínuo, sendo repetidos até completar a superfície de revestimento. Zorgi (2008) complementa informando que o designer precisa ter domínio sobre os efeitos causados na composição pela repetição, além de prestar atenção na criação e nos elementos conhecidos da linguagem visual (como o ponto, a linha, a forma, a textura, a cor, a direção, entre outros que componham seus projetos).

A cor é tão importante quanto à forma e os padrões. Segundo Farina, Perez e Bastos (2006) a cor "abre" ou "fecha" o canal de comunicação entre a atração ou a repulsa, além de servir para ampliar ou diminuir o espaço em uma decoração ou ambiente, pois uma superfície clara parece sempre maior do que uma escura.

A mensagem presente nas padronagens está além do objeto ou da superfície, ela agrega significados semânticos que traduzem todo um referencial cultural e único. As padronagens misturam cores, formas, texturas, aspectos complexos que, além da função decorativa, permitem uma transfiguração simbólica (GUBERT, 2011).

Para Freitas (2012) o design de superfície, é como um design de interfaces, está presente na pele dos produtos e das superfícies conferindo a estes uma carga comunicativa, transmitindo informações sígnicas que são percebidas por meio dos sentidos como cores, texturas e grafismos. Com isso, o design de superfície "como elemento compositivo no design de interiores, seja ocupando uma grande área, seja 
um detalhe" contribui consideravelmente na construção da identidade do ambiente (GUBERT, 2011, p.121). Dentro do ambiente existe o design de interiores e a decoração de interiores, áreas que possuem suas diferenças. O design de interiores preocupa-se com a criação dos ambientes, seja por manipulação espacial ou decoração. Já a decoração de interiores preocupa-se apenas com a parte decorativa, sem alterar a estrutura já existente. Porém, ambos agregam identidade ao ambiente. (GUBERT, 2011; BROKER E STONE, 2007).

Segundo Gubert (2011), os designs de superfícies encontrados nos ambientes de interiores são os têxteis (móveis estofados, cortinas, tapetes, almofadas, lençóis, colchas), materiais cerâmicos/porcelanatos (revestimentos para uso em paredes, fachadas, pisos, azulejos), e materiais sintéticos/artificias (laminados, vinilicos, emborrachados).

Os azulejos são utilizados como "proteção para o patrimônio, como as condições climáticas, ou ainda como um elemento decorativo" (CAMPOS NETO, 2011). Segundo Rüthschilling (2008, p.39), esses revestimentos cerâmicos para paredes e pisos "representam um importante campo de aplicação do design de superfície".

Também existe a categoria dos papeis informada por Rubim (2004), que hoje está muito presente nos ambientes, onde se encontram os papéis de parede que podem ser aplicados em quadros, paredes ou até móveis.

O papel de parede ganhou sua nobre reputação no século XVIII, atingindo um nível de perfeição que fez dele um símbolo de requinte e excelência nas artes decorativas francesas. [...] A grandeza e a ambição dos criadores de papel de parede, a complexidade da composição, a qualidade da impressão e da sutileza e riqueza da paleta de cores, [...] o papel de parede [...] deixou sua marca na história da decoração de interiores (THIMBAUT-POMERANTZ, 2009, apud TECKEMEIER, 2012).

Possui um conjunto de elementos que influenciam no resultado final do papel de parede, um deles é a paleta de cores que é muito importante para composição da sua padronagem. Para Fraser e Banks (2007) essa paleta de cores pode ser harmoniosa e suave ou berrante e multiforme, onde padrões com cores fortes podem dar efeitos dramáticos, mas os desenhos repetitivos com cores suaves podem ser calmos e serenos. Em casos de ambientes pequenos, o papel de parede pode ampliá-lo ou diminuí-lo dando a sensação de que é maior ou menor do que aparenta ser (TECKEMEIER, 2012).

Com o avanço da tecnologia e a invenção do meio digital/virtual, o consumidor começou a permanecer mais em casa, muitos até trabalham em sua própria casa como empresas terceirizadas ou autônomas. Segundo Almeida (2012) "a busca pelo conforto, beleza e praticidade atinge a maioria das pessoas em suas habitações, possibilitando identidade personalizada a cada espaço, em busca desses resultados". Por passarem mais tempo em casa e nos seus escritórios é necessário sentirem-se bem nesses locais, fazendo com que as pessoas busquem por personalização e uma identidade própria para os seus ambientes, seja ele qual for. Mancuso (2015) afirma que em termos psicológicos, não existe nada que substitua o "bem estar" de quem habita e desfruta do espaço.

Os consumidores, em geral, têm essa necessidade de personalização e customização: a sociedade busca sua identidade em produtos e bens e, a 
massificação destes pode prejudicar a diferenciação individual. No ramo escolhido, decoração de interiores, isso é ainda mais evidente. Os lares e seus ambientes são os lugares onde as pessoas podem se expressar. São eles um dos poucos ambientes onde elas têm liberdade de deixar do seu jeito próprio, evidenciando gostos e personalidades. Poder ter em seu ambiente, local muitas vezes de refúgio pessoal, produtos sob encomenda é algo que valoriza o espaço. E seu custo não é alto perante os produtos massificados do mercado, o que torna possível produzir papeis de parede customizados, inovadores e personalizáveis. (ALMEIDA, 2012)

Hoje o papel de parede está em alta novamente e fornece identidade ao ambiente, pois "traz vida e cor e faz com que as paredes cantem" (THIMBAUTPOMERANTS, 2009, apud TECKEMEIER, 2012). A partir deste estudo, a pesquisa de campo buscou encontrar uma hipótese referente ao motivo pelo qual as pessoas compram design de superfície.

\section{DISCUSSÃO DOS RESULTADOS}

Após a coleta de dados foram sublinhadas nas respostas dos questionários dos participantes, palavras-chave que respondem de forma direta o problema que está sendo estudado, conforme o Quadro 1.

Quadro 1 - Palavras-chave informadas pelos Arquitetos e Designers dividas em categorias.

\begin{tabular}{|c|c|c|}
\hline Profissional & Palavras-chave & Categoria \\
\hline Arquiteto 1 & Trará exclusividade e personalidade. & Personalização \\
\hline Arquiteto 2 & $\begin{array}{l}\text { Facilidade de colocação e troca, praticidade; baixo tempo em obra; } \\
\text { ausência de cheiro; variadas estampas ampliam sua utilização. }\end{array}$ & Funcionalidade \\
\hline Arquiteto 3 & Harmonização do ambiente; ambiente mais convidativo. & Personalização \\
\hline Arquiteto 4 & Segue tendência do comércio, da mídia. & $\begin{array}{l}\text { Não se encaixa } \\
\text { em nenhuma }\end{array}$ \\
\hline Arquiteto 5 & $\begin{array}{l}\text { Para não deixar o ambiente monótono, pintam uma ou mais } \\
\text { paredes de uma cor diferente ou aplicar textura; Cliente deseja } \\
\text { algo com desenhos diferenciados ou sofisticados não gere sujeiras } \\
\text { nem grandes obras. }\end{array}$ & Funcionalidade \\
\hline Arquiteto 6 & $\begin{array}{l}\text { Transforma seu ambiente e deixa luxuoso; possível criar várias } \\
\text { composições; dar destaques em detalhes determinantes. }\end{array}$ & Personalização \\
\hline Arquiteto 7 & $\begin{array}{l}\text { Recurso rápido e barato para a mudança nos espaços de } \\
\text { interiores. }\end{array}$ & Funcionalidade \\
\hline Arquiteto 8 & Valorização dos ambientes. & Personalização \\
\hline Arquiteto 9 & Dinâmica visual nos ambientes; Criar ambiente temático. & Personalização \\
\hline Arquiteto 10 & Deixar o ambiente mais sofisticado e aconchegante. & Personalização \\
\hline Arquiteto 11 & Dar mais identidade; Fica mais personalizado. & Personalização \\
\hline Arquiteto 12 & Tornar o ambiente com personalidade, único e exclusivo. & Personalização \\
\hline
\end{tabular}




\begin{tabular}{|c|c|c|}
\hline Designer 1 & $\begin{array}{l}\text { Diferencial das opções; Substitui pintura; material lavável e de } \\
\text { longa duração. }\end{array}$ & Funcionalidade \\
\hline Designer 2 & $\begin{array}{l}\text { Busca do belo a serviço do prazer; retrate nossa personalidade; } \\
\text { Não dispensa decoração bem planejada, primando pela } \\
\text { praticidade e apelo visual atraente; valor econômico e valor } \\
\text { estético. }\end{array}$ & $\begin{array}{l}\text { Personalização e } \\
\text { Funcionalidade }\end{array}$ \\
\hline Designer 3 & $\begin{array}{l}\text { Identidade com o gosto do cliente; pessoa que entra no ambiente } \\
\text { sentir sensações; torna o ambiente único e diferenciado. }\end{array}$ & Personalização \\
\hline Designer 4 & $\begin{array}{l}\text { Aspecto diferenciado e personalizado no ambiente; algo exclusivo; } \\
\text { chama a atenção por não ter sido visto igual em nenhum lugar. }\end{array}$ & Personalização \\
\hline Designer 5 & $\begin{array}{l}\text { Identidade única aos projetos os tornam exclusivos e especiais; } \\
\text { para dar personalidade ao projeto. }\end{array}$ & Personalização \\
\hline Designer 6 & Espaços exclusivos e práticos. & $\begin{array}{l}\text { Personalização e } \\
\text { Funcionalidade }\end{array}$ \\
\hline Designer 7 & $\begin{array}{l}\text { Além de decorativa, é usado para esconder fissuras e juntas de } \\
\text { dilatação. }\end{array}$ & $\begin{array}{l}\text { Disfarçar } \\
\text { Imperfeições }\end{array}$ \\
\hline Designer 8 & Dar diversos sentidos e sensações aos ambientes. & Personalização \\
\hline Designer 9 & Atualizar um ambiente sem, muito custo e de forma rápido. & Funcionalidade \\
\hline Designer 10 & $\begin{array}{l}\text { Da vida aos ambientes, conferindo sofisticação, elegância e } \\
\text { personalização; Facilidade de aplicação, rápida e limpa; Grande } \\
\text { durabilidade. }\end{array}$ & $\begin{array}{l}\text { Personalização e } \\
\text { Funcionalidade }\end{array}$ \\
\hline Designer 11 & $\begin{array}{l}\text { Diversidade de texturas e estampas; são laváveis e fáceis de } \\
\text { manter, de fácil manuseio; o custo do rolo e do profissional a } \\
\text { contratar para sua aplicação é bem menor. }\end{array}$ & $\begin{array}{l}\text { Personalização e } \\
\text { Funcionalidade }\end{array}$ \\
\hline Designer 12 & $\begin{array}{l}\text { Estética, luxo, harmonização entre o ambiente com a modulação; } \\
\text { sensação de escolha para o bem estar. }\end{array}$ & Personalização \\
\hline
\end{tabular}

Fonte: Elaborado pelo autor

De acordo com o quadro 1 foi estabelecido cinco categorias: personalização, funcionalidade, personalização e funcionalidade, disfarçar imperfeições, e não se encaixa em nenhuma. A partir disso foi possível a criação de dados estatísticos para melhor compreender o resultado da pesquisa. A seguir, será analisada a pesquisa em 2 grupos, o primeiro constituído pelos Arquitetos e o segundo constituído pelos Designers (vide figura 1), e no geral constituído pelos 2 grupos (vide figura 2).

\section{ARQUITETOS}

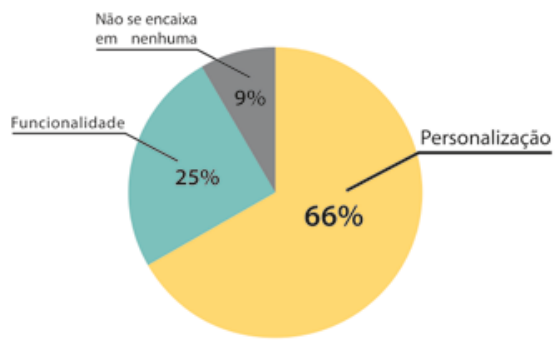

\section{DESIGNERS}

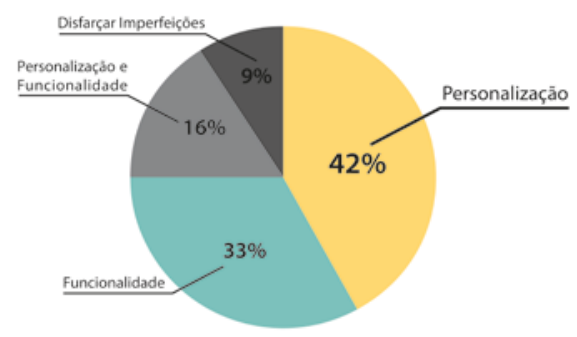

Figura 1 - Grupo 1 (Arquitetos) e Grupo 2 (Designers).

Fonte: Elaborado pelo autor

A figura 1 mostra que a maioria dos profissionais, Arquitetos (66\%) e Designers (42\%), afirmaram que as pessoas compram design de superfície primeiramente pela personalização, em segundo momento pela funcionalidade (Arquitetos $25 \%$ e Designers 33\%). Já para os Designers, possui mais dois motivos, o terceiro seria a 
personalização juntamente com a funcionalidade com $16 \%$ e o quarto motivo seria para disfarçar imperfeições com $9 \%$.

É notável que os designers possuem uma percepção divergente dos arquitetos, isso pode ocorrer devido os designers buscarem aplicar a estética juntamente com a funcionalidade (vide quadro 1), levando em consideração as duas características ao desenvolver um produto. Já os arquitetos demonstram possuir uma visão voltada mais para a estética, harmonização e equilíbrio (vide quadro 1), do que para a funcionalidade, quando o produto se relaciona com design de superfície. De acordo com Löbach (2001) e Munari (2008) estabelecem três funções fundamentais que são observadas ao projetar: função prática, estética e simbólica.

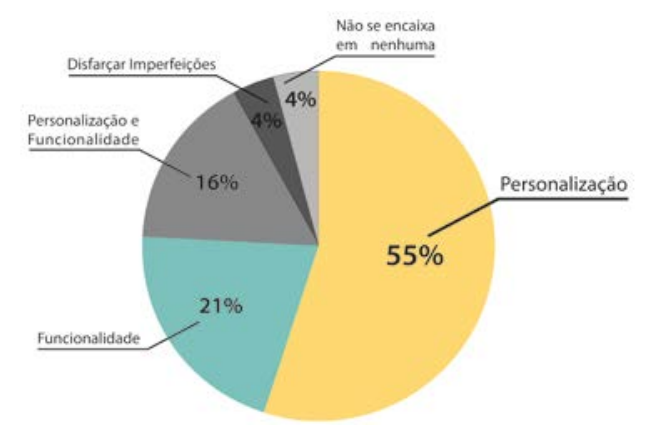

Figura 2 - Ambos os Grupos.

Fonte: Elaborado pelo autor

Porém, em uma visão geral composta por ambos os profissionais (vide figura 2) a ordem das hipóteses permanece igual. Onde o principal motivo pelo qual as pessoas, da região de Balneário Camboriú, compram design de superfície continua sendo a personalização (55\%, onde $33,85 \%$ são arquitetos e $21,16 \%$ são designers). Em segundo lugar por causa da funcionalidade $(21 \%$, onde $12,6 \%$ são arquitetos e $8,4 \%$ são designers). E em terceiro lugar a personalização juntamente com a funcionalidade (16\% composta apenas por designers).

Entretanto, no resultado geral, a porcentagem dos designers continua sendo menor que a dos arquitetos em relação ao motivo ser a "personalização". Porém, isso não influencia na pesquisa, já que $16 \%$ dos designers acreditam que o motivo é a "personalização com a funcionalidade" e apenas $8,4 \%$ deles informam ser a "funcionalidade", evidenciando a importância da personalização. A seguir será apresentada a conclusão da discussão teórica desenvolvida e da coleta de dados.

\section{CONCLUSÃO}

Foi possível alcançar todos os objetivos propostos, tanto o objetivo geral, a descoberta de uma hipótese que mostre o motivo pelo qual as pessoas compram design de superfície para ambientes na região de Balneário Camboriú, como os específicos: ter conhecimento das aplicações do design de superfície; seleção e identificação de quais aplicações do design de superfície são comercializáveis; e verificação do problema por meio de pesquisa qualitativa com 12 arquitetos e 12 designers.

O design de superfície pode ser aplicado em produtos: têxteis (estampas em tecidos) tais como móveis estofados, cortinas, tapetes, almofadas, lençóis, colchas, entre outros; cerâmicos e porcelanatos que são revestimentos para uso em paredes, fachadas e pisos, como azulejos, lajotas, vasos, entre outros; de papeis que podem ser 
aplicados em quadros, paredes ou até móveis; materiais sintéticos e artificiais como laminados, vinilicos, adesivos, emborrachados, vidros. As aplicações mais comercializáveis são as têxteis, cerâmicas, porcelanatos e papeis de parede (que podem ser feitos de tecidos, adesivo ou papel).

$\mathrm{Na}$ discussão dos resultados descobriu-se que os profissionais possuem percepções divergentes. O design busca aplicar a estética juntamente com a funcionalidade em seus projetos, já os arquitetos demonstram possuir uma percepção mais voltada para a estética (harmonização e equilíbrio), do que para a funcionalidade, quando o produto se relaciona com design de superfície. Porém, isso não influencia na pesquisa, pois de acordo com os Designers $21,6 \%$ informam que o motivo é a "personalização", 16\% deles acreditam que o motivo é a "personalização com a funcionalidade", e apenas $8,4 \%$ deles informam ser a "funcionalidade", evidenciando a importância da personalização (com 55\%, onde 33,85\% são arquitetos e $21,16 \%$ são designers).

Com isso, é possível concluir que a hipótese pelo qual as pessoas da região de Balneário Camboriú compram design de superfície é por causa da personalização, já que $55 \%$ dos profissionais responderam essa informação. Dessa forma, foi possível atingir a solução do problema que era tornar essa hipótese científica. Para trabalhos futuros, sugere-se realizar uma pesquisa quantitativa buscando a opinião dos usuários para confirmar a hipótese identificada neste artigo, tanto na região de Balneário Camboriú como em outras regiões e estados.

\section{REFERÊNCIAS}

ALMEIDA, Leila M. S. Estamparia para papel de parede para impressão em baixa tiragem. 2012. Disponível em: <http://conferencias.utfpr.edu.br/ocs/index.php/sicite/ 2012/paper/viewFile/257/692>. Acesso em: 17 Set. 2013. Não paginado.

ANTUNES, Ricardo. Guia do Ilustrador. 2007. Disponível em: <http://www.guiadoilustrador.com.br/>. Acesso em: 28 abr. 2016.

ASSOCIAÇÃO BRASILEIRA DOS ILUSTRADORES PROFISSIONAIS. Flavio Roberto Mota e Grego. Documento de análise para regulamentação e reconhecimento da profissão de ilustrador no brasil (dossiê ilustração). 2006. Disponível em:

<http://www.abipro.org/?scrid=Artigos.2006-04_Dossie_Flavio_Roberto_Mota_ Grego>. Acesso em: 28 abr. 2016

BARDIN, Laurence. Análise de Conteúdo. Lisboa, Portugal; Edições 70, LDA, 2009.

BROKER, Graeme; STONE, Sally. Basic Interior Architecture: Form + Structure. Lousanne: Ava, 2007.

CASTAGINI, Andrea da Silva; BALVEDI, Fabiane. Ilustração digital e animação. 2010. Disponível em: <http://portaldoprofessor.mec.gov.br/storage/materiais/ 0000015331.pdf>. Acesso em: 15 Set. 2013.

FARINA, Modesto; PEREZ, Clotilde; BASTOS, Dorinho. Psicodinâmica das cores. $5^{\circ}$ Edição, São Paulo: Edgard Blucher, 2006.

FRASER, Tom; BANKS, Adam. O guia completo da cor. São Paulo: Editora Senac, 2007. 
FREITAS, Renata $O$. Teixeira de. Os processos geradores das ações comunicacionais táteis no design de superfície. 2012. Disponível em: <http://ebooks.pucrs.br/edipucrs/ anais/apcg/edicao10/Renata.Teixeira.pdf>. Acesso em: 17 Set. 2013.

GUBERT, Marjorie Lemos. Design de Interiores: a padronagem como elemento compositivo no ambiente contemporâneo. 2011. Disponível em:

<http://www.lume.ufrgs.br/handle/10183/36398>. Acesso em: 23 Ago. 2012.

LÖBACH, Bernd. Design Industrial: bases para a configuração dos produtos industriais. São Paulo: Editora Blucher, 2001.

MANCUSO, Clarice. Arquitetura de interiores e decoração: a arte de viver bem. 9a edição, São Paulo: Sulina, 2015.

MDESIGN BRASIL. Um espaço aberto para novos olhares: design de superfície. 2010. Disponível em: <http://www.mdesignbrasil.com.br/pt/dicas/?id=223\&title=Design_ de_Superficie>. Acesso em: 26 Ago. 2013.

MUNARI, B. Das coisas nascem coisas. 2. ed. São Paulo, SP: Martins Fontes, 2008.

CAMPOS NETO, Carlos Alberto Henrique de. Design de Superfície: Análise dos Azulejos do bairro histórico da Cidade Velha em Belém do Pará. 2011. Disponível em:

$<$ http://www.desenhandoofuturo.com.br/anexos/anais/design_e_sociedade/design_d e_superficie_analise_dos_azulejos_do_bairro_historico_da_cidade_velha_em_belem_ do_para.pdf>. Acesso em: 17 Set. 2013. Não paginado.

NOBLE, Ian. Commercial illustration: Mixing traditional approaches and new techniques. ROTOVISION: Switzerland, 2003.

RABELO, Juliana M.; MATOS, Adriana Leiria Barreto. O Perfil do llustrador do PósModerno. 2011. Disponível em: <http://www.revistaprex.ufc.br/index.php/EXTA/ article/view/32/45>. Acesso em: 21 Ago. 2013.

RIBEIRO, Ana Isabel do Coito Jesus. Cultura visual e práticas educativas na disciplina de desenho. 2010. Disponível em: <http://repositorio.ul.pt/handle/10451/3590>. Acesso em: 16 Set. 2013.

RINALDI, Ricardo Mendonça. A contribuição da comunicação visual para o design de superfície. 2009. Disponível em: <http://www.athena.biblioteca.unesp.br/exlibris /bd/bba/33004056082P0/2009/rinaldi_rm_me_bauru.pdf>. Acesso em: 17 Set. 2013.

RODRIGUES, William Costa. Metodologia Científica. 2007. Disponível em: <http://professor.ucg.br/sitedocente/admin/arquivosupload/3922/material/willian\%2 Ocosta\%20rodrigues_metodologia_cientifica.pdf>. Acesso em: 09 Jun. 2013.

RUBIM, Renata. Desenhando a Superfície. São Paulo: Edições Rosari, 2004.

RÜTHSCHILLING, Evelise A. Design de Superfície. Porto Alegre: Ed. da UFRGS, 2008.

. Design de Superfície: prática e aprendizagem mediadas

pela tecnologia digital, 2002. Tese (Doutorado em Informática da Educação) Faculdade de Educação, Universidade Federal do Rio Grande do Sul, Porto Alegre.

. Núcleo de Design de Superfície. 2006. Disponível em:

<http://www.nds.ufrgs.br/novo/index.html>. Acesso em: 30 abr. 2016. 
SCHWARTZ, Ada Raquel Doederlein. Design de Superfície: por uma visão projetual geométrica e tridimensional. 2008. Dissertação (Mestrado em Desenho Industrial) Universidade Estadual Paulista, Bauru. Disponível em: <http://repositorio.unesp.br/ handle/11449/89726>. Acesso em: 30 abr. 2016.

STEAGALL, Jaqueline. 0 processo de criação de ilustrações em mídias digitais. 2008. Disponível em: <http://www.sapientia.pucsp.br//tde_busca/arquivo.php?cod Arquivo=6905 $>$. Acesso em: 16 Set. 2013.

TECKEMEIER, Thaís. Proposta de desenvolvimento de linha de papel de parede. 2012. Disponível em: <http://tconline.feevale.br/tc/files/4902_469.pdf>. Acesso em: 17 Set. 2013. Não paginado.

ZORGI, Vanessa. Azulejo como suporte do design gráfico. 2008. Disponível em: <http://ged.feevale.br/bibvirtual/Monografia/MonografiaVanessaZorgi.pdf >. Acesso em: 11 Set. 2011. 